\title{
Definiendo los límites: matrimonio y continencia en la Iglesia del Imperio sasánida
}

Héctor Ricardo Francisco

IMHICIHU-CONICET / Universidad de Buenos Aires, Argentina hectorfrancisco@conicet.gov.ar

\section{Resumen}

El presente artículo analiza los fundamentos teológicos y eclesiológicos de las normativas 'anti-ascéticas' de finales del siglo V en la Iglesia del Imperio sasánida. Al respecto, sostendremos que las normativas tendientes a sostener el matrimonio como condición para el status clerical fueron el resultado de complejas fuerzas que operaban tanto desde el exterior como en el interior de la Iglesia. En concreto, las normativas en torno al matrimonio clerical desarrollados en la Iglesia sasánida obedecían a la necesidad de definir la naturaleza de la autoridad espiritual ante los desafíos de otras comunidades religiosas.

Palabras clave ascetismo matrimonio Antigüedad Tardía Iglesia de Oriente

\section{Establishing Boundaries: Marriage and continence in the Church of the Sasanian Empire}

\begin{abstract}
This paper examines the theological and Ecclesiological principles underlying the anti-ascetical regulations in the Church of the East under Sasanian rule. It will hold that the regulations aimed at sustain Marriage as condition to attain clerical status were the product of diverse forces outside and inside the Church. More specifically, regulations on clerical Marriage were the product of the need to define the nature of spiritual authority before the challenges of other religious communities.
\end{abstract}

Tomás de Margā relata en su Libro de los gobernadores (compuesto en el siglo IX) una anécdota acaecida a principios del siglo VII en el gran monasterio de monte 'īzlā. Ésta involucraba al célebre monje Elías de Hīrthā, discípulo del
Keywords

Asceticism Marriage Late Antiquity Church of the East 
1. Sobre la reforma monástica de Abraham ver los trabajos de Sabino Chialà (2005:49-96) y Florence Jullien (2008). Sobre la figura de Mãr Elías ver el trabajo de Fiey (1965:639-647).

2. Tomás de Margā, Libro de los Gobernadores, 27.

3. Tomás de Margā, Libro de los Gobernadores, 29.

4. Acto significativo ya que uno de los elementos claves de la reforma de Abraham fue la tonsura que distinguía a los monjes diofisitas (en forma de corona) de los miafisitas (dejando el cabello en forma de cruz). Tomás de Margā, Libro de los Gobernadores, 40-41, en especial nota 4.

5. Tomás de Margā, Libro de los Gobernadores, 32.

6. Synodicon Orientale, 115. gran reformador del monacato sirio oriental, Abraham de Kaškar. ${ }^{1}$ De acuerdo con la anécdota, Elías había descubierto que varios monjes de la comunidad cohabitaban con mujeres y que, peor aún, habían engendrado hijos con ellas. El autor, precisa que estos monjes "se habían casado y tomaron esposas ( $n s a b h \bar{u}$ wahtaph $\bar{u}$ neše $\bar{e}$ ) a las que llevaron a las celdas exteriores (lqelyāthā baryāthā) en las que vivían". ${ }^{2}$ El santo, advertido por el ruido de las ruecas usadas por las mujeres y los niños pequeños jugando, se acercó para preguntarles qué hacían allí. Los niños contestaron "pertenecemos a este lugar y nuestros padres son tal y cual" . ${ }^{3}$ El escandalizado monje se dirigió al abad, llamado Babāy, para presentar una acusación contra los monjes corruptos. El abad, presionado por el carisma de Elías, reunió a toda la comunidad para juzgar a los transgresores. Luego de haber sido encontrados culpables de la acusación "les arrancaron el hábito de la soledad (l'eskhìmā d'ìhìday $\bar{u} t h \bar{a})$, abrieron la tonsura de sus cabezas (tra 'ù sūphārāa drēšayhōn), ${ }^{4}$ los expulsaron junto con sus esposas e hijos y, encendiendo un fuego, quemaron sus celdas". 5

Pero el celo rigorista de Elías no concluyó con la expulsión de los monjes transgresores. De inmediato, el ermitaño dirigió su furia contra uno de los monjes más influyentes del monasterio, el célebre Jacobo de Lašōm, a quien acusó de haber tolerado la corrupción en la comunidad. Asediado por las furibundas acusaciones de Elías, Jacobo y un grupo de hermanos abandonó el monasterio para fundar el monasterio de Bēth 'Abhē. Como ha señalado, Paolo Bettiolo (2007) esta anécdota refleja la tensión entre dos formas diferentes de ejercicio de la autoridad espiritual fundadas en dos concepciones teológicas antagónicas de la disciplina monástica.

Este incidente resulta significativo en tanto sugiere la pervivencia de ambigüedades en torno al celibato tanto de monjes como del clero de la Iglesia del Oriente en una fecha relativamente tardía. El propósito de este trabajo no es volver sobre el problema de la disciplina monástica en el monacato siriooriental. Por el contrario nos interesa señalar la vigencia de dichas ambigüedades, que se ve confirmada por un canon promulgado por un sínodo convocado por el Católico de Mār Ezequiel (567-581) que condenaba a los monjes que "secuestran mujeres empujadas por el pecado y se atreven a decir que no es pecado hacer cosas que son inconvenientes". ${ }^{6}$

Tanto el incidente en el gran monasterio de monte '̄̄zlā como el canon sinodal son ecos tardíos de la problemática relación entre continencia y matrimonio en la Iglesia de Oriente. Esta relación problemática se remonta al siglo V cuando se produjo un debate dentro de la Iglesia de Oriente en torno al celibato tanto de clero como de monjes. Esquemáticamente podemos caracterizar este debate en la tensión entre el ascetismo y una supuesta tendencia anti-ascética que habría emergido en la segunda mitad del siglo V. De acuerdo con una visión muy difundida entre los especialistas, esta supuesta corriente anti-ascética dentro de la Iglesia del imperio sasánida habría sido el producto de las influencia de las similares tendencias dominantes en la aristocracia irania (de matriz zoroastriana). Así, los obispos cristianos asociados a la corte, en tanto también eran miembros de la elite gobernante sasánida, habrían impulsado en los sínodos de finales del siglo $\mathrm{V}$ un conjunto de disposiciones que imponían el matrimonio (y la procreación) como condición para el status clerical (Selb, 1981:149-153).

Como señalamos, existe un consenso académico que considera esta corriente anti-ascética en el cristianismo sasánida como una influencia del zoroastrismo, que veía en la procreación, derivada de una sexualidad hetero-normativa, una acción piadosa que colaboraba con el mantenimiento del orden de la creación 
dispuesto por Ahura Mazda (Mendoza Forrest, 2011) y, por lo tanto, un deber moral (Buch, 1919:85) (Nigosian:1999) (Williams, 1997;1989). Desde esta perspectiva el imperativo de un clero casado, desde el Católico hasta el último miembro del bajo clero, habría constituido una estrategia de acomodación a la moral dominante de la sociedad sasánida. Pero, cuando ponemos esta estrategia en el marco más amplio del proceso de constitución del matrimonio cristiano en la Iglesia de Oriente, constatamos una contradicción. En efecto, la flexibilidad que habría demostrado el clero cristiano al aceptar la moral matrimonial de los magos contrasta con el cerrado rechazo a otras prácticas asociadas al zoroastrismo (como el matrimonio incestuoso, la poligamia) o al judaísmo (el levirato) que parecen haber sido corrientes entre las elites cristianas del imperio persa (Panaino, 2008).

No es nuestra intención negar por completo la influencia de factores externos en la imposición de un modelo clerical que privilegiaba el matrimonio y la procreación. Pero, como intentaremos demostrar, el contexto que generó las normativas 'anti-ascéticas' de finales del siglo $\mathrm{V}$ fue el resultado de complejas fuerzas que operaban tanto desde el exterior como en el interior de la Iglesia.

El debate en torno al matrimonio clerical tiene una larga historia que se remonta a tiempos patrísticos. Las sensibles diferencias entre el oriente bizantino y el occidente latino en torno a las condiciones por las cuales era lícito casarse para los sacerdotes (sobre todo desde la reforma gregoriana) interesaron tanto a historiadores de la Iglesia como a historiadores sociales. La bibliografía al respecto es considerable y no vamos a hacer un análisis exhaustivo de ella. Nos basta con hacer algunas precisiones que pueden ayudarnos en nuestro posterior análisis. A pesar de las (a menudo aparentes) divergencias en torno a las normas que regulaban el matrimonio clerical, ambas tradiciones partían de la identificación entre continencia y santidad. En efecto, resulta obvio sostener que la continencia sexual fue un elemento crucial en la definición del clero como un cuerpo de especialistas en lo sagrado (Brown, 1988). En tal sentido, podemos sostener sin riesgo a exagerar que -en el litoral mediterráneo- el cristianismo se situaba en una continuidad con una tradición arraigada en el judaísmo del segundo templo y que, con matices, se puede encontrar también en el paganismo clásico.

Pero, fuera del litoral mediterráneo, el cristianismo se desarrolló en un contexto social y cultural distinto. La historia del cristianismo en el contexto iranio entre los siglos II y IV es mal conocida. Los pocos testimonios acerca del período fueron producidos en los siglos V y VI y la gran cantidad de inconsistencias y contradicciones inclinan a sospechar que las fuentes proyectaban en el pasado situaciones imperantes en el momento de su composición (Jullien; Jullien, 2002). Esta situación se revierte desde el siglo V cuando las fuentes cristianas producidas en el contexto sasánida empiezan a ser más abundantes. En tal sentido, existe un consenso en que la Iglesia de Oriente experimentó un conjunto de transformaciones cuyo común denominador fue la lenta pero segura imposición de la ortodoxia nicena y de un modelo jerárquico que (al menos en sus líneas más generales) era similar al de la Iglesia occidental. Estas transformaciones supusieron la convergencia de diversas fuerzas, a menudo contradictorias. Por un lado, un proceso de institucionalización de la autoridad episcopal que se apoyaba en la progresiva incorporación (y hasta cierto punto adaptación) de los cánones de los sínodos occidentales. Por otro lado, la constitución de un monacato ortodoxo que remplazó formas ascéticas primitivas dominadas por tendencias heterodoxas. Por último, la consolidación de una elite cristiana (laica y episcopal) integrada 
al marco más amplio de la aristocracia sasánida. Dicha integración supuso, primariamente, su incorporación a las redes de solidaridad y patronazgo en cuya cúspide se encontraba el Šāhānšāh.

En este punto no es necesario recordar que, como en cualquier sociedad premoderna, las relaciones de parentesco constituían elementos fundamentales en la formas de construcción del poder social. Por lo tanto, la formulación de normativas específicamente cristianas que codificaban las relaciones parentales no sólo afectaba la definición del liderazgo al interior del cuerpo de creyentes, sino que también regulaba las formas de relacionarse con otras comunidades religiosas, primariamente judíos, maniqueos y zoroastrianos. Así, para comprender las particularidades del matrimonio clerical en la Iglesia de Oriente es necesario inscribirlo en el marco más amplio de la definición del matrimonio cristiano. Dicha definición estuvo determinada no sólo por las tradiciones (bíblicas y patrísticas) heredadas sino también por el diálogo con un marco normativo dominado por los postulados teológicos del zoroastrismo y por la interacción en el seno de una aristocracia compuesta por varias comunidades cultuales con las que los cristianos entablaron un diálogo usualmente conflictivo.

Las disposiciones sinodales en torno al matrimonio impactaron de manera directa en la relación entre la comunidad cristiana y su entorno. En efecto, el matrimonio era considerado un contrato regulado por el derecho sasánida que contemplaba la pluralidad jurídica y la superposición de marcos normativos que eran a menudo contradictorios. ${ }^{7}$ En tal sentido, la emergencia de disposiciones tendientes a regular el matrimonio afectaba la integración de la elite cristiana en el contexto más amplio de la sociedad imperial.

Un momento crucial en el proceso de definición del matrimonio cristiano fue el período comprendido por el gran Católico reformador Mār Abā I (544-552) y sus sucesores. Tanto Mār Abā como los Católicos de la segunda mitad del siglo VI realizaron reiterados y sistemáticos intentos para constituir un marco normativo en el que el matrimonio cristiano estuviera controlado por le elite clerical. Entre las numerosas medidas tomadas en este período se destacan la derogación de las normativas anteriores que permitían el matrimonio del Católico, los metropolitanos y los obispos. Así, entre la segunda mitad del siglo VI y la primera mitad del VII se impuso lentamente un modelo episcopal en el que se privilegiaba el origen monástico (Payne, 2015:93-126).

No vamos a analizar en profundidad la naturaleza de dichas reformas ni haremos una evaluación de sus alcances. Sólo nos interesa resaltar que el impulso reformador fue fundamental en la cristalización de una identidad específicamente cristiana que, sin embargo, no afectaba su integración en la elite imperial. En tal sentido, la reforma supuso un corte abrupto con un modelo formalizado en las últimas décadas del siglo V. En aquel período, se impuso una noción del sacerdocio que difería del modelo monástico. Como veremos, el debate en torno del matrimonio clerical fue funcional en la definición de la autoridad cristiana ante los desafíos internos y externos. En este sentido, la característica más notable de los sínodos de la segunda mitad del siglo V no fue tanto la flexibilidad en las reglas que administraban el matrimonio clerical sino en la ruptura con la identificación entre continencia y santidad.

En lo que resta de este trabajo analizaremos el impacto del debate en torno al matrimonio del clero en la definición de la autoridad cristiana en el imperio persa sasánida. Sin descuidar las evidentes influencias externas, nos 
concentraremos en los efectos teológicos y eclesiológicos derivados de la asociación entre matrimonio legítimo, procreación y santidad. En consecuencia, analizaremos las circunstancias que habilitaron la exigencia del matrimonio como condición previa para el estatus clerical que se extendía desde el Católico hasta los miembros del clero menor. Esta condición no sólo derivaba de las presiones que empujaban a las elites cristianas a adoptar las costumbres de sus vecinos zoroastrianos. Desde un punto de vista eclesiológico, la imposición de un modelo clerical basado en la obligatoriedad del matrimonio atacaba las bases mismas de poder de los disidentes teológicos (miafisitas y mesalianos) cuya autoridad estaba sustentada en la práctica ascética.

La cohabitación de hombres célibes y mujeres está atestiguada en la Iglesia de Oriente al menos desde el siglo IV. Por ejemplo, Aphrahat en su exposición sexta aceptaba con muchas reservas el matrimonio de Hijos e Hijas del pacto (bnay wabnath qyāmā) pero sólo como paliativo contra la lujuria $($ regtā $) .{ }^{8}$ Por el contrario, el autor anónimo del Liber Graduum desaprobaba el matrimonio de los líderes cristianos -llamados gmìrēe 'perfectos' - como extensión de su condena general a la procreación. En efecto, la antropología del Liber Graduum presuponía una oposición radical entre la naturaleza angélica del hombre antes de la caída y la reproducción animal posterior a aquella. ${ }^{9}$ De esta manera, la procreación sexual era el resultado de la intervención demoníaca sin la cual los hombres se hubieran reproducido de una manera alternativa (Minov, 2014).

Ya volveremos al Liber Graduum. Por ahora, nos basta recordar que su teología contenía muchos elementos que lo vinculaban al encratismo y al maniqueísmo. A diferencia de la ortodoxia cristiana, en la teología maniquea la procreación implicaba la reproducción del mundo material, por lo que era percibida como negativa (Beduhn, 2000). Así, los líderes de la Iglesia maniquea (los Electi) se diferenciaban de los simples fieles (Auditores) entre otras cosas por consagrarse a la más absoluta continencia sexual. Las primeras referencias al debate en torno al matrimonio en la Iglesia persa no pueden aislarse de un debate a mayor escala que estaba determinado por una cierta permeabilidad de los cristianos al discurso contrario a la procreación del maniqueísmo. En efecto, los borrosos límites que separaban ambas comunidades habilitaban espacios de discusión teológico-antropológica.

En las dos primeras décadas del siglo $\mathrm{V}$ fueron convocados los primeros sínodos que apuntaban a estructurar la Iglesia de Oriente de acuerdo a los cánones occidentales. Aunque la ortodoxia nicena imperante en el Imperio romano no parece haber estado ausente en el siglo anterior, no fue hasta las primeras décadas del siglo $\mathrm{V}$ que ella adquirió (con muchas dificultades) un estatus hegemónico del otro lado de la frontera. Las tensiones entre el imperativo del celibato y las prácticas de cohabitación de hombres y mujeres célibes apenas encontraron un eco indirecto en ellos. De hecho, la única referencia al respecto se encuentra en el sínodo de Mār Isaac (410). Este canon se limitaba a reproducir (con sensibles diferencias) el canon tercero del concilio de Nicea que

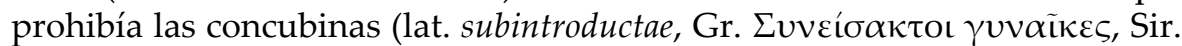
'āmūryāthā) que cohabitan con obispos, sacerdotes, diáconos, subdiáconos o hijos del pacto; pero en nada legislaba respecto a esposas legítimas. ${ }^{10}$

En cambio, la continencia clerical (junto con el matrimonio legítimo) se convirtió en un problema de primer orden en los sínodos de las últimas décadas del siglo V. El sínodo (en retrospectiva considerado ilegítimo) reunido en Bēth Lapat del año 484 y presidido por el obispo Barșaūmā de Nísibis, y los sínodos de Seleucia y Ctesifón de los años 486 y 497 fueron la manifestación
8. Aphrahaț, Exposiciones, VI, 4. Ver la traducción de Pierre (1988:375-376).

9. Cfr. Liber Graduum, 1.3. col.336

10. Cfr. Sínodo de Mār Isaac, Canon III, Synodicon Orientale, 24. 
11. Miguel el sirio, Crónica II, 123-124.

12. Bar Hebraeus, Chronicon Ecclesiasticum, 65-67.

13. Bar Hebraeus confunde el sínodo

de Bēth Lapaț del (484) con el sínodo de Bēth 'Edray convocado un año después para conciliar ambas facciones. de un clima de reforma que se extendía tanto a temas teológicos y como disciplinarios. Por un lado, la tradición reconoce que durante estos sínodos se impuso una cristología diofisita extrema (mal llamada nestoriana) inspirada en las obras de Teodoro de Mopsuestia y Narsaī. Por otro lado, estos sínodos apuntaron a reforzar la disciplina interna de la Iglesia. Esta disciplina alcanzaba tanto al clero de las diócesis como a los monjes y, en menor medida, a los laicos para quienes se prescribían prácticas asociadas al paganismo, la herejía y el judaísmo.

Los primeros intentos de definir el matrimonio cristiano en general, y el matrimonio como condición para el sacerdocio en particular, están relacionados con el famoso obispo Barșaūmā de Nísibis (460-491). De acuerdo con los testimonios, Barșaūmā convocó un sínodo que se reuniría en la ciudad de Gundēšāpūr-Bēth Lapaṭ (metrópolis de la diócesis de Bēth Hūzayē) en febrero del año 484 con dos objetivos explícitos: primero imponer la ortodoxia diofisita en la Iglesia de Oriente y, segundo, establecer una reforma disciplinaria del clero. Pero, sobre todo, el sínodo parece haber sido convocado como un ataque directo contra el Católico Babhōy (457-484) a quien acusaba de corrupción y alta traición.

Los eventos que rodean la convocatoria del sínodo están lejos de ser claros y es probable que las fuentes (muy tardías) hayan exagerado (por distintas razones y con diferentes argumentos) el papel de Barșaūmā. Por supuesto, la interpretación de los eventos varía de acuerdo a las perspectivas confesionales. Los historiadores miafisitas consideraban al Católico Babhōy como una víctima de las maquinaciones del obispo de Nísibis mientas acusaban directamente a este último por el relajamiento de la disciplina clerical y por la imposición del nestorianismo en la Iglesia de Oriente. Por ejemplo, Miguel el sirio (s. XII) -quien se apoyó en el testimonio de Marūthā de Takrit (s. VII)- destacaba la concurrencia entre herejía y relajamiento de la disciplina clerical, mientras que apuntaba directamente al obispo de Nísibis por ambas circunstancias. Miguel no sólo responsabilizaba a Barṣaūmā (y al célebre maestro de la escuela de Edesa, Narsaī) por haber introducido el nestorianismo en el imperio sasánida, sino que además los acusaba de haber convocado un sínodo con el único fin de establecer la obligatoriedad del matrimonio para todo el clero persa y, de esa manera, legitimar su cohabitación con una prostituta. ${ }^{11}$

Por su parte, Gregorio Bar Hebraeus (s. XIII) ${ }^{12}$ desarrolló la polémica con argumentos un poco más elaborados. En efecto, éste atribuyó una intencionalidad primariamente geopolítica a las operaciones del obispo Barșaūmā, quien convenció al monarca Peroz I (457-484) de que la obediencia de sus súbditos cristianos dependía de que éstos se diferenciaran teológicamente de sus correligionarios romanos. Con el apoyo real, el obispo de Nísibis persiguió a los ortodoxos (miafisitas) y reunió un sínodo en el que se impuso la herejía nestoriana y, al mismo tiempo, estableció el matrimonio obligatorio para sacerdotes y obispos. ${ }^{13}$ Cualesquiera sean los argumentos, para ambos historiadores, la herejía y la corrupción del clero fueron el producto de las maquinaciones del ambicioso obispo que utilizó el matrimonio como su principal herramienta (Bruns, 2005:14).

Por el contrario, las fuentes de la Iglesia de Oriente invierten los términos de la ecuación, atribuyendo el relajamiento de la disciplina eclesiástica al Católico Babhōy, quien habría sido el culpable de permitir la simonía y el relajamiento de la moral del clero. En cambio, Barșaūmā intervino en defensa de la disciplina y la ortodoxia. Resulta interesante notar que las fuentes contemporáneas (como 
la Crónica de Arbelas y la Historia de Karkhā dBēth Slōkh) no hacen referencia alguna a los eventos de finales del siglo V. Nuestros principales testimonios son, por el contrario, dos crónicas árabe-cristianas compuestas alrededor del siglo XI: la Crónica de Siirt ${ }^{14}$ y el Liber Turris. ${ }^{15}$ Ambas señalan de manera más o menos directa a Babhōy como el responsable de la corrupción en la Iglesia. En particular, la Crónica de Siirt lo acusa de permitir el casamiento ilegal de "sacerdotes y monjes" (alruhban walkahnatun). Por esta y otras transgresiones, el sínodo condenó al Católico. Mientras tanto, Barșaūmā redactó una carta en la que concedía el matrimonio para "sacerdotes y monjes que no podían vivir en continencia". ${ }^{16}$

Una lectura atenta tanto de la Crónica de Siirt como del Liber Turris permite destacar dos cosas. Primero, a diferencia de los historiadores miafisitas ambas crónicas involucraron en el debate no sólo al clero diocesano sino también a los monjes. Este detalle no resulta intrascendente ya que, como veremos, contradice el contenido mismo de los cánones sinodales. En segundo lugar, de ambas fuentes se desprende que la anuencia de Barșaūmā a aceptar el matrimonio de sacerdotes (él mismo estaba casado) y monjes parece haber sido apenas una concesión a la corrupción imperante por el desgobierno del Católico.

Si los testimonios de los historiadores no ofrecen un panorama coherente del sínodo de Bēth Lapat, las grandes compilaciones canónicas de los siglos XII y XIII nos dan apenas testimonios fragmentarios. Los cánones de este sínodo no se han conservado, salvo por algunos fragmentos citados por Elías de Nísibis (s. XII) y 'Abdī̌̌ō' de Nísibis (s. XIII). Son fragmentos de los cánones 12, 13, 18 y otros no especificados que condenaban la simonía (13), la intervención de las autoridades no cristianas en la elección de los obispos (12), el recurso a jueces no cristianos en conflictos internos de la Iglesia (18), y establecían de manera muy general las prohibiciones relativas al matrimonio (incesto, poligamia, rapto de esposas, etc.). ${ }^{17}$ Pero ninguno de ellos hace referencia directa al matrimonio clerical. Por supuesto, el silencio no es prueba de ausencia pero resulta curioso que, a pesar de la insistencia de los historiadores en la centralidad del sínodo de Bēth Lapaț en la imposición del matrimonio como condición para el sacerdocio, se haya perdido todo testimonio del texto original. Como ya ha destacado Gero (1981), la atribución a Barșaūmā de un canon que innovaba estableciendo el matrimonio de clérigos y monjes parece haber sido el resultado de la polémica interconfesional. No obstante, a pesar de sus diferencias de énfasis, tanto los autores sirio-occidentales como los sirio-orientales coincidían en un esquema narrativo común en el que disciplina eclesiástica y ortodoxia fueron parte de una misma ecuación.

En febrero del año 486 los obispos del Imperio persa se reunieron en la capital imperial para sanar el cisma producido por las desavenencias entre Barșaūmā y el (en ese momento) ya fallecido Católico Babhōy. Reunidos ante el recientemente electo Católico Acacio, los obispos promulgaron tres cánones de contenidos conexos. El primero proclamaba, como respuesta a la herejía miafisita, la ortodoxia de la cristología de Teodoro de Mopsuestia. Los otros dos cánones regulaban la disciplina clerical. En estrecha relación con el canon primero, el canon segundo prohibía el establecimiento de monjes y monasterios en la vecindad de las ciudades y restringía la participación de los ascetas en la vida litúrgica de las ciudades y aldeas que contaran con un clero establecido. En el párrafo inicial, los obispos establecían una estrecha relación entre la infiltración herética y los monjes giróvagos que desafiaban la autoridad episcopal. Tanto Peter Bruns (2005) como Gero (1981) señalan correctamente que el canon segundo fue la respuesta a la infiltración dentro de los monasterios de la herejía miafisita indicada en el canon primero.
14. Crónica de Siirt, 99.

16. Crónica de Siirt, 7.8; Liber Turris, 36 
18. Synodicon Orientale, 56.

19. Al respecto ver Bruns (2005).

20. Synodicon Orientale, 56-57.

22. Sobre el concilio de Ancira ver Joannou (1962:64) y Schulthess (1908:37-38). Cfr. el canon VI del concilio en Trullo.
El tercer (y último) canon prohibía a los obispos oponerse al matrimonio de los miembros del clero de su diócesis. Resulta interesante analizar con detenimiento los argumentos esgrimidos por los obispos reunidos en el sínodo. El canon está dividido en tres partes, la primera refiere los males que cayeron sobre la Iglesia a causa del adulterio y la fornicación (bgawrā wabzanyūthā) y de las burlas de los paganos al respecto. En la segunda parte, los obispos establecen que:

(...) nadie entre nosotros haga prevalecer esta promesa (šūwdayä) en su clero por la fuerza (qțirāa'itt), sea entre los sacerdotes de las aldeas, sea entre los hijos del pacto que están bajo su autoridad sino que su enseñanza esté de acuerdo con los libros santos y que por su propia debilidad reconozca la debilidad de otros. ${ }^{18}$

Ante el adulterio y la fornicación el canon recomendaba una actitud flexible que contemplara "de acuerdo a los libros sagrados" las debilidades del clero local. Las bases teológicas de esta forma económica de ejercer la autoridad espiritual puede encontrarse en una tradición ascética sirio-oriental que se manifestará con mayor claridad en las obras de Isaac de Nínive (Bettiolo, 2007:329-331). Con esta paráfrasis el canon reconocía el origen de los males de la Iglesia tanto en los excesos del ascetismo extremo como en el ejercicio inflexible de la autoridad episcopal. La segunda parte del canon concluía con una cadena de las citas neotestamentarias (Mt. 19: 11, 12; 1 Cor. 7: 1, 2; 8, 9) que, comentadas a la luz de la exégesis del 'intérprete' (como se conocía a Teodoro de Mopsuestia) ${ }^{19}$ legitimaban el matrimonio clerical.

La tercera y última parte del canon instituía (invocando la autoridad de 1 Tim. 3:1-2) al matrimonio y la continencia como dos alternativas igualmente válidas pero excluyentes. ${ }^{20}$ Pero introducía como excepción a esta regla el caso de los diáconos que ya hubieran recibido la ordenación y que desearan unirse a una esposa. A ellos se les permitiría "unirse a una mujer en matrimonio correcto y legítimo y liberarse de la costumbre antigua ('ayāda 'atīqthā) que, a causa del relajamiento de los libertinos (raphyūthā dzalīlēe), es dañada y convertida en burla por parte de los de afuera (men barrāye $)^{\prime \prime} .{ }^{21}$

Por esa "costumbre antigua" se refería al canon décimo del concilio de Ancira ${ }^{22}$ que establecía que los diáconos debían manifestar su deseo de casarse en el momento de su ordenación, de lo contrario no podrían casarse una vez ordenados. Resulta significativo que este desplazamiento con respecto a la tradición se presentara como una reacción a los excesos ascéticos de los monjes que, no obstante, cohabitaban con mujeres. En efecto, el canon proseguía destacando la necesidad de velar por las costumbres de los diáconos:

Un obispo no conferirá la ordenación del diaconado a un hombre de su ciudad o de las aldeas que están bajo su autoridad sin antes informarse si mantuvo buenas conductas (dūbarē țābé) dignas de la ordenación para la cual se presenta, y además, si tuvo una unión legítima y procreación de hijos (šawtāphūthā namūsīthā wmawldā dabnayē), para hacer desaparecer cuidadosamente de la Iglesia de Cristo toda arrogancia y ostentación de los que sostienen doctrinas erróneas (yūlphānēța ayê) que llaman al matrimonio y la procreación un mal y que aplacan su deseo (regthāhōn) por el adulterio, la fornicación y artificios malvados (bgawrā wabzanyūthā wșen ānthā bišăthā). [...] Enseñamos que aquel que eligió voluntariamente la abstención del matrimonio debe habitar una habitación solitaria, en la pureza y la continencia y no disiparse. ${ }^{23}$ 
Las disposiciones del sínodo divergían de los cánones occidentales aceptando el matrimonio de los diáconos con posterioridad a la ordenación. Este desplazamiento se justificaba aludiendo a las 'doctrina erróneas' que rechazan el matrimonio y la procreación. Esas ‘doctrinas erróneas' eran lo que los obispos interpretaban como las inclinaciones maniqueas del encratismo mesaliano muy difundido entre los monjes. Ese encratismo contradecía la antropología de Teodoro de Mopsuestia en la que la procreación era parte integral de la naturaleza humana. ${ }^{24}$

En suma, las disposiciones en favor del matrimonio de diáconos previamente ordenados deben ser leídas a la luz de los ataques dirigidos contra el ascetismo extremo y las limitaciones a las funciones litúrgicas de los monjes del canon segundo. En efecto, mientras que este último intervenía ante la indisciplina monástica que, en apariencia, servía de sustento a la herejía miafisita, el canon tercero atacaba un elemento constitutivo del carisma de estos misioneros itinerantes: su pretensión de una pureza excepcional, derivada de su praxis ascética. Esta pretensión era descripta como simple hipocresía y el sínodo proponía como solución no sólo dejar sin efecto las disposiciones de los sínodos occidentales que prohibían el matrimonio a los diáconos ordenados sino que ponía como condición para el diaconado el casamiento y la procreación. Esta disposición se extendía a los presbíteros, quienes podían casarse luego de la ordenación o incluso tener un segundo matrimonio. De nuevo, la fundamentación de este distanciamiento de los cánones occidentales se presenta como una reacción contra el encratismo "Porque el matrimonio legítimo y la procreación de hijos, sea antes o después del sacerdocio, son una cosa buena y aceptable a Dios". ${ }^{25}$

El sínodo convocado por el Católico Mār Acacio supuso un desvío significativo con respecto a los cánones occidentales. Pero el objetivo del sínodo no parece haber sido tanto imponer el matrimonio como condición para el sacerdocio y los monjes como refutar a aquellos que impugnaban el matrimonio clerical desde una posición rigorista. Los 'excesos' ascéticos eran identificados con la extensión de un movimiento monástico que desafiaba la autoridad de los obispos de origen aristocrático y cuya inserción en la aristocracia sasánida los ponía en contacto con las costumbres mundanas asociadas a la corte zoroastriana. Estos nuevos núcleos de poder eclesial desafiaban al mismo tiempo la ortodoxia que, con dificultades, intentaban imponer el obispo Barșaūmā y los maestros exiliados de la escuela de Nísibis (expulsados de la Edesa romana). Esa ortodoxia estaba primariamente asociada a la cristología y antropología de Teodoro de Mopsuestia.

En consecuencia, el reconocimiento del matrimonio de sacerdotes y diáconos previamente ordenados reforzaba los canales tradicionales que conformaban la autoridad eclesiástica. Así, la supuesta flexibilidad de los obispos ante clérigos casados no fue provocada tanto por la interpelación de las costumbres matrimoniales de la elite zoroastriana como por la filtración de una corriente rigorista que presentaba un doble desafío. Por un lado una autoridad carismática basada en el ascetismo individual y aislado de los canales tradicionales basados en el parentesco y, por otro lado, la penetración de corrientes rigoristas identificadas con el maniqueísmo.

Ante esta nueva situación, un grupo de obispos reformadores (vinculados a Barșaūmā) entendieron que las viejas tradiciones de cohabitación de hombres y mujeres célibes debían ser puestas bajo control. Aquello que preocupaba a esos obispos reunidos en el 486 era combatir lo que interpretaban como
24. Y también en Narsaī, cfr. Gignoux (1968:211).

25. Synodicon Orientale, 58 
26. La bibliografía en torno al mazdakismo es tan extensa como variada. Remitimos al lector a los trabajos de Otakar Klima (1957), Ehsan Yarshater (1983) y Patricia Crone (1991).

27. Synodicon Orientale, 63. tendencias maniqueas de los ascéticos rigoristas y las situaciones ambiguas que se generaban por la cohabitación con mujeres. En este punto no podemos dejar de notar que probablemente este sea el contexto de la circulación (aunque no necesariamente de producción) de textos rigoristas como el Liber Graduum. En contra de los argumentos de su autor, la defensa del matrimonio y la procreación que ejercía el sínodo aseguraba la disciplina eclesiástica contra un movimiento anárquico que atentaba contra una red de autoridad construida en torno al metropolitano de la capital y cuya legitimidad dependía de la colaboración entre las elites locales y el Católico.

La última y decisiva escala en la imposición del matrimonio y la procreación como condición para el sacerdocio fue durante el catolicado de Mār Babay (497-503), que coincidió con el breve reinado del Šāhānšāh Zāmāsp I (496-498). Como es bien sabido el reinado de Zāmāsp fue un breve interludio en el extenso reinado de su hermano Kawād I (488-496/498-531) cuyo reinado estuvo signado por el intento de reforma religiosa y social del sacerdote zoroastriano Mazdak. Éste, recordemos, propuso una completa reforma social que incluía -entre otras cosas- el establecimiento de la propiedad comunal de la tierra y la comunidad de mujeres. ${ }^{26}$

El mismo año de su ascenso, Babāy convocó un sínodo cuyo objetivo principal fue fijar definitivamente el matrimonio como condición necesaria al estatus clerical en todos sus estamentos. En tal sentido, Babāy no se limitó a repetir las disposiciones y argumentos de sus predecesores sino que los llevó más allá estableciendo la validez del matrimonio de los arzobispos y del Católico mismo. La introducción al extenso documento que enumera las decisiones del sínodo destaca que su convocatoria se produjo a instancias del Šāhānšāh, quien promulgó un edicto (saqrā) convocando un concilio:

[...] para que los obispos sometidos a su autoridad se presentaran ante él (Babāy) e hicieran una reforma (tūrāșâ) relativa al matrimonio legítimo y la procreación de niños (zaūwāgā taqnā wmawldā dabnayê) y para todos los clérigos (bnay qyāmā) de todos lados. ${ }^{27}$

La apelación a la autoridad de un rey pagano en la convocatoria no es nueva en los sínodos de la Iglesia de Oriente pero, en el contexto político y religioso en el que se inserta, resulta significativa. Al transformar la reforma en voluntad del rey, Babāy reafirmaba su papel como legítimo intermediario entre la comunidad cristiana y el monarca. Al mismo tiempo, daba a las decisiones sinodales una fuerza coactiva que la equiparaba con la legislación imperial. No obstante, es probable que esta invocación a la voluntad imperial fuera un artilugio retórico que encubría lo que probablemente haya sido una iniciativa emanada del Católico. El texto redactado por el sínodo continuaba:

Nosotros hemos realizado las reformas convenientes a nuestro pueblo y a nuestro rebaño en el asunto del matrimonio y a la procreación de niños y hemos permitido que desde el patriarca hasta el más bajo del pacto pueda contraer matrimonio puro (dzawāwgā dakyā) con sólo una mujer y engendrar hijos y servir. Y admitimos además, y sólo en este punto, la asamblea que se realizó en el territorio de Bēth Hūzayē en la ciudad de Bēth Lapaț en el año 27 del rey Perōz. ${ }^{28}$

El fragmento tiene dos elementos significativos. En primer lugar, esta es la única referencia explícita al sínodo de Bēth Lapaṭ como impulsor del matrimonio episcopal. En segundo lugar, aunque no es posible sostener 
una correlación directa entre las reformas de Mazdak y las disposiciones sinodales sobre el matrimonio, es indudable que eran respuestas diversas a un mismo problema, esto es, la redefinición de las bases teológicas y éticas en las que se basaba la autoridad espiritual. La extensión de las disposiciones del sínodo de Acacio relativo al casamiento de diáconos y presbíteros previamente ordenados, al católico y los obispos daba sanción formal a una situación de hecho. Naturalmente, mantenía abierto el oficio episcopal a un amplio conjunto de los miembros de la elite laica. Pero si tomamos en cuenta que una parte significativa de ella apelaba a prácticas rechazadas por los sínodos anteriores (poligamia, incesto, etc...) el canon puede ser también interpretado como una limitación tanto para ascetas rigoristas como para aquellos cuyas prácticas matrimoniales se desviaban de las nuevas normas que los sínodos buscaban imponer.

Aunque los cánones de los sínodos de finales del siglo V reflejan la preocupación de los Católicos y una parte significativa del episcopado por legitimar el matrimonio clerical, este no fue el único discurso circulante. Ya vimos que textos rigoristas como el Liber Graduum alcanzaron una amplia difusión entre el clero y en círculos monásticos inconformistas. Otras alternativas, menos extremas se encuentran en la literatura hagiográfica, en particular en los Acta de los Mártires Persas. Algunos textos describen a mujeres consagradas (hijas del Pacto), diáconos y presbíteros rechazando el perdón real a cambio del matrimonio. ${ }^{29}$ No obstante, los testimonios resultan particularmente escuetos y resulta muy difícil establecer si su contexto de producción está de alguna manera relacionado con las disposiciones sinodales.

Un testimonio revelador se encuentra en la Crónica de Siirt en un fragmento que probablemente sea la traducción árabe de un texto compuesto en la segunda mitad del siglo VI. La anécdota está enmarcada en el contexto de la persecución dirigida contra los maniqueos a finales del siglo III y hace referencia a una historia ocurrida durante el catolicado del semilegendario Mār Papā (280-316) y el reinado del Šāhānšăh Wahrām II (274-293). Este monarca se había mostrado especialmente hostil hacia los discípulos de Manī $\mathrm{y}$, habiéndose enterado de que "los maniqueos se proclamaban nazarenos (nașri) y se vestían como ellos y despreciaban el matrimonio y la procreación como el Católico y los obispos", ordenó que los cristianos fueran también perseguidos. Éstos protestaron ante el rey diciendo:

Los maniqueos [...] consideran que el matrimonio (al-zawağ) es impuro (nağas). Pero los nazarenos [...] enseñan que el matrimonio es bueno y lo prescriben en sus escrituras. Pero sus jefes (rūasā ahum) se privan de él para que el matrimonio no les impida hacer aquello para lo que han sido ordenados, esto es, la administración de su rebaño, la oración y la intercesión por el mundo y sus gentes, por el rey y el reino. ${ }^{30}$

Aunque la escena se da en el marco de un debate entre el rey y los obispos, sus argumentos resuenan como la respuesta a las impugnaciones de los sínodos al rigorismo ascético. Esto no resulta extraño si tomamos en cuenta la tendencia de la literatura martirial sirio-oriental a componer largos diálogos ficticios para polemizar con propios y ajenos. No obstante, los argumentos no son de orden teológico sino de orden práctico. El redactor de la anécdota rechaza cualquier vinculación entre continencia clerical y maniqueísmo estableciendo las diferencias entre ambos. Mientras que para los primeros el rechazo al matrimonio y la procreación es fruto de su dualismo ontológico, para los segundos era una cuestión esencialmente pastoral. En otras palabras, el ascetismo cristiano
29. Una lista (no exhaustiva) de referencias al matrimonio como opción al martirio en $A M S$ II, 236; 256-257; 309; 590; 361-368. AMSIV, 138; Brock (1978); cfr. Delehaye (1907:90).

30. Crónica de Siirt, 27-28. 
no derivaba de un rechazo metafísico al mundo creado por Dios sino a la necesidad de establecer una jerarquía eclesial basada en la superioridad de la continencia por sobre la procreación.

No podemos sostener que exista una relación directa entre estos testimonios y los debates suscitados a finales del siglo V. Sin embargo, las coincidencias en temas y argumentos apuntan al menos a un clima de época. Tanto los Acta de los Mártires Persas como el fragmento de la Crónica de Siirt revelan que la concepción episcopal que buscaban imponer los sínodos, distó de gozar de una posición hegemónica. Por el contrario, la fugacidad de su influencia y la emergencia de visiones alternativas son indicadores de la naturaleza coyuntural de tales medidas.

En conclusión, la imposición de un modelo de clero casado y relevado de la continencia parece haber sido un hecho coyuntural pero significativo en el proceso de constitución del clero de la Iglesia de Oriente. La forma más radicalizada de este modelo (que incluía al Católico, los metropolitanos y los obispos) no sobrevivió más allá de mediados del siglo VI, pero algunas particularidades (como el casamiento de clérigos previamente ordenados) alcanzó una vida más duradera.

Las circunstancias que explican las 'particularidades' del modelo clerical de los sínodos del siglo V son tanto teológicas como eclesiológicas. Desde el primer punto de vista, la interacción con los zoroastrianos parece haber jugado un papel secundario aunque sensible. En cambio, el desafío del encratismo y el maniqueísmo puede que haya jugado un papel determinante. En especial, la capacidad de este último por romper las barreras confesionales (en particular influyendo en la cultura monástica) constituyó un desafío mayor para la jerarquía cristiana ortodoxa a lo largo del siglo V. Conjuntamente, la extensión del movimiento mazdakista (al que podemos considerar de alguna manera influido por las ideas de Manī) con sus tendencias sincréticas impulsó a los líderes cristianos a defender el lugar de la procreación en el plan divino.

Desde el punto de vista eclesial, las normativas relativas al matrimonio clerical tenían un doble efecto. Por un lado, la rápida (e incontrolada) difusión de un movimiento monástico impregnado de rigorismo encratita obligó a fijar una línea que demarcaba el límite entre los monjes y el sacerdocio, restringiendo la participación de aquellos en la administración de los misterios y sometiéndolos al poder episcopal.

De tal manera, la compatibilidad entre matrimonio, procreación y estatus clerical apuntaba a reforzar los canales tradicionales de autoridad eclesiástica que se basaban en el monopolio que ejercían las familias aristocráticas cristianas sobre el oficio episcopal. En efecto, para la segunda mitad del siglo V, el cristianismo había logrado notables progresos en los escalones más bajos de la aristocracia sasánida, en especial las elites urbanizadas de Iraq. El episcopado era la manifestación formal de un liderazgo que se canalizaba por mecanismos tradicionales como el patronazgo o las relaciones de parentesco. Para estas elites, el cristianismo era un componente más en su identidad. Pero no era el único. Además, una parte sustancial de su identidad dependía de su participación en la cultura dominante. En este contexto, el celibato clerical era potencialmente conflictivo para un episcopado mundano y aristocrático.

Pero este modelo no sobreviviría al cambio de siglo. La imposición de un modelo episcopal célibe y de origen monástico a lo largo del siglo VI fue una 
respuesta alternativa a las tensiones derivadas de la integración de la elite cristiana en el marco de las elites imperiales. Esa respuesta fue posible gracias a la concurrencia de cambios a mayor escala. Las reformas administrativas emprendidas por Xusrō I, que redefinieron las bases mismas del poder en la sociedad sasánida, encontraron su eco en la Iglesia en la completa reorganización del clero cristiano. Al modelo centralizado de la monarquía le correspondió un modelo eclesiológico monárquico en el que el clero y los monjes quedaban bajo control episcopal. Esto permitió la emergencia de un episcopado formado en las grandes escuelas monásticas diferenciado de las elites laicas, y organizado jerárquicamente en torno a la figura del Católico. 


\section{Q Bibliografía}

\section{Fuentes}

» AMS, Bedjan, P. (1891-1894). Acta Martyrum et Sanctorum Syriace. Paris-Leipzig: Harrasowitz.

»Aphrahaț, Exposiciones, Pierre, M. J. (1988). Aphraate le Sage persan. Les Exposés I: Exposés I-X. SC 349. Paris: Cerf.

» Bar Hebraeus, Chronicon Ecclesiasticum, Abbeloos, J. B. \& T. J. Lamy. (1872). Gregorii Barhebraei: Chronicon Ecclesiasticum III. Paris-Lovaina: Peeters.

»Crónica de Siirt, Scher, A. (1911). Histoire nestorienne (Chronique de Séert). Seconde partie (I), en Patrologia Orientalis 7.2. Paris : Firmin \& Didot; Scher, A. \& J. B. Périer (1908). Histoire nestorienne inédite: (chronique de Séert). Première partie. (I), en Patrologia Orientalis 4.3. Paris: Firmin \& Didot.

» Liber Graduum, Kmoskó, M. (1926). Liber Graduum, Patrologia syriaca III. Paris: Firmin \& Didot.

» Liber Turris, Gismondi, H. (1899). Maris, Amri et Slibae: De Patriarchis nestorianorum commentaria ex codicibus vaticanis. Roma: De Luigi.

» Miguel el sirio, Crónica, Chabot, J. B. (1899-1910). Chronique de Michel le Syrien. 4 vols. Paris: E. Leroux.

»Synodicon Orientale, Chabot, J. B. (1902). Synodicon Orientale. Paris: Klincksieck.

" Tomás de Margā, Libro de los Gobernadores, Wallis Budge, E. A. (2003 [1893]). The Book of Governors: The Historia Monastica of Thomas, Bishop of Margâ, A. D. 840. Piscattaway: Gorgias Press.

\section{Bibliografía secundaria}

» Beduhn, J. D. (2000). The Manichaean Body in discipline and Ritual. Baltimore: Johns Hopkins University Press.

» Bettiolo, P. (2007). "Contrasting Styles of Ecclesiastical Authority. The monastic life in the Church of the East at the beginning of the Seventh Century". En: Camplani, A.; Filoramo, G. (eds.), Foundations of Power and Conflicts of Authority in Late-Antique Monasticism (OLA 157). Leuven: Peeters, 297-331.

» Brock, S. P. (1978). "A martyr at the Sasanid court under Vahran Il: Candida", AB 96, 167-181.

»Brown, P. (1988). El cuerpo y la sociedad. Barcelona: Crítica.

» Bruns, P. (2005). "Barsauma von Nisibis und die Aufhebung der Klerikerenthaltsamkeit im Gefolge der Synode von Beth-Lapat (484)", Annuarium Historiae Conciliorum 37.1, $1-42$.

» Buch, M. (1919). Zoroastrian ethics. Baroda: A.G. Widgery. 
" Cerutti, M. V. (1982). "Tematiche "encratite" nello zoroastrismo pahlavico". En: Bianchi, U. (ed.), La Tradizione dell'enkrateia. Milán: Edizioni dell'Ateneo, 637-668.

" Chialà, S. (2005). Abramo di Kashkar e la sua comunità. La Rinascita del monachesimo sirio-orientale. Comunità di Bose: Quiqajon.

"Crone, P. (1991). "Kavad's Heresy and Mazdak's Revolt", Iran 29, 21-42.

»Delehaye, H. (1907). Les Versions grecques des Actes des Martyrs Persans. Textes grecs et traductions. Patrologia Orientalis 2.4. Paris: Firmin-Didot.

» Fiey, J. M. (1965). Assyrie chrétienne. Contribution à l'étude de l'histoire et de la géographie ecclésiastiques et monastiques du Nord de l'Iraq, I. Beirut: Imprimiere Catholique.

" Gëro, S. (1981). Barsauma of Nisibis and Persian Christianity in the fifth century, CSCO 426, Sub. 63. Leuven: Peeters.

» Gignoux, P. (1968). Homélies de Narsaï sur la Création. Patrologia Orientalis 34.3-4. Paris: Brepols.

» Joannou, P-P. (1962). Fonti Discipline Generale Antique. Roma: Tipografia ItaloOrientale.

"Jullien, C.; Jullien, F. (2002). Apôtres des confins. Processus Missionaires Chrétiens dans l'empire Iranien. Bures-sur-Yvette: Groupe pour l'Étude de la Civilisation du Moyen-Orient.

"Jullien, F. (2006). "Le monachisme chrétien dans l'empire iranien (IVe-XIVe siècles)". En: Gyselen, R. (ed.), Chrétiens en terre d'Iran: implantation et acculturation. Paris: Peeters, 143-184

" Jullien, F. (2008). Le monachisme en Perse. La réforme d'Abraham le Grand, père des moines del'Orient. Vols. CSCO 622, Subsidia 121. Lovaina: Peeters.

» Klima, O. (1957). Mazdak. Geschichte einer sozialen Bewegung im Sassanidischen Persien. Praga: Nakladatelství Československé Akademie.

» Macuch, M. (2007). "The Pahlavi Model Marriage Contract in the Light of Sasanian Family Law". En: Macuch, M.; Maggi, M.; Sundermann, W. (eds.), Iranian Languages from Iran and Turan. Wiesbaden: Harrasowitz, 183-204.

" Macuch, M. (2014). "The Case against Mār Abā, the Catholicos, in the Light of Sasanian Law", Aram 26, 47-58.

" Mendoza Forrest, S. (2011). Witches, Whores, and Sorcerers: The Concept of Evil in Early Iran. Texas: University of Texas Press.

" Minov, S. (2014). "Marriage and Sexuality in the Book of Steps: from Encratism to Orthodoxy". En: Heal, Ch.; Kitchen, R. (eds.), Breaking the Mind. Washington: The Catholic University of America Press, 221-261.

"Nigosian, S.A. (1999). "Zoroastrian Perception of Ascetic culture". En: Ishwaran, K. (ed.), Ascetic culture. Renunciation and Wordly Engagement. Leiden: Brill, 4-18.

»Panaino, A. (2008). "The zoroastrian Incestuous Unions in Christian Sources and Canonical Laws: Their (distorted) Aetiology and some other problems". En: Jullien, C. (ed.), Controverses des Chrétiens dans l'Iran Sassanide. Paris: AAEI, 69-87.

"Payne, R. (2015). A State of Mixture: Christians, Zoroastrians, and Iranian Political Culture in Late Antiquity. Oakland: University of California Press.

"Schulthess, F. (1908). "Die syrischen Kanones der Synoden von Nicaea bis Chalcedon", AKGWG n.f. 10.2. 
"Selb, W. (1981). Orientalisches Kirchenrecht. Band I. Die Geschichte des Kirchenrechts der Nestorianer (von den Anfängen bis zur Mongolenzeit). Viena: OAW.

"Williams, A.V. (1989). "The body and the boundaries of Zoroastrian spirituality", Religion 19.3, 227-239.

»Williams, A.V. (1997). "Zoroastrism and the Body". En: Coakley, S. (ed.), Religion and the Body. Cambridge: Cambridge University Press, 155-166.

» Yarshater, E. (1983). "Mazdakism". En: Cambridge History of Iran, III: The Seleucid, Parthian and Sasanian Periods. Cambridge: Cambridge University Press, 991-1024. 